They are frequently multiple and bilateral, and present at a mean age of 50.7 yrs [7]. The most common histological subtypes are hybrid oncocytic (50\%) and chromophobe (34\%) renal cell carcinoma, while clear cell, oncocytoma and papillary renal cell cancer are less frequently found [7]. Radiographic screening is recommended, with a typical strategy involving abdominal computed tomography and/or renal ultrasound at the time of diagnosis, followed by interval screening every $3-$ 5 yrs [8]. Parenchyma-sparing surgery is recommended given the risk of development of further tumours [7]. In line with these recommendations, all participants in the study by FRÖHLICH et al. [1] were screened for kidney manifestations by abdominal ultrasound and none were identified.

The importance of recognising the possibility of a diagnosis of Birt-Hogg-Dubé syndrome in patients with familial recurrent pneumothorax, with or without characteristic skin findings, lies in undertaking surveillance for renal tumours, a potentially lethal feature of this syndrome.

\section{G. Warwick*, L. Izatt ${ }^{\#}$ and E. Sawicka}

*Dept of Thoracic Medicine, St Vincent's Hospital, Sydney, Australia. "Dept of Clinical Genetics, Guys Hospital, London, and "Dept of Respiratory Medicine, Princess Royal University Hospital, Orpington, Kent, UK.

\section{REFERENCES}

1 Fröhlich BA, Zeitz C, Mátyás G, et al. Novel mutations in the folliculin gene associated with spontaneous pneumothorax. Eur Respir J 2008; 32: 1316-1320.

2 Birt AR, Hogg GR, Dubé WJ. Hereditary multiple fibrofolliculomas with trichodiscomas and acrochordons. Arch Dermatol 1977; 113: 1674-1677.

3 Toro JR, Glenn G, Duray P, et al. Birt-Hogg-Dubé syndrome: a novel marker of kidney neoplasia. Arch Dermatol 1999; 135: 1195-1202.

4 Roth JS, Rabinowitz AD, Benson M, Grossman ME. Bilateral renal cell carcinoma in the Birt-Hogg-Dubé syndrome. J Am Acad Dermatol 1993; 29: 1055-1056.

5 Linehan WM, Pinto PA, Srinivasan R, et al. Identification of the genes for kidney cancer: opportunity for disease-specific targeted therapeutics. Clin Cancer Res 2007; 13: 671s-679s.

6 Toro JR, Wei MH, Glenn GM, et al. BHD mutations, clinical and molecular genetic investigations of Birt-Hogg-Dubé syndrome: a new series of 50 families and a review of published reports. J Med Genet 2008; 45: 321-331.

7 Pavlovich CP, Walther MM, Eyler RA, et al. Renal tumors in the Birt-Hogg-Dubé syndrome. Am J Surg Pathol 2002; 26: 1542-1552.

8 Welsch MJ, Krunic A, Medenica MM. Birt-Hogg-Dubé syndrome. Int J Dermatol 2005; 44: 668-673.

\title{
Impulse oscillometry in comparison to spirometry in pregnant asthmatic females
}

\section{To the Editors:}

Asthma complicates $3-8 \%$ of pregnancies [1, 2] and early diagnosis and optimal management of the condition seems necessary. However, spirometry as a clinical measure of airway disease mainly depends on subjects efforts during forced expiratory manoeuvres. Considering the high prevalence of respiratory symptoms and breathlessness in pregnancy and the limited functional capacity and mobility of the diaphragm because of the growing foetus [3], an easier, more rapid screening test that does not require patient cooperation would be ideal. Our study aimed to evaluate the correlation between spirometry and impulse oscillation technique (IOS) parameters to reveal the utility of IOS parameters in diagnosis of airflow obstruction in pregnant females.

In total, 125 pregnant females were categorised in three groups of asthmatics: 1) 40 physician-diagnosed asthmatics, on the basis of National Asthma Education and Prevention Program guidelines [4]; 2) 35 probable asthmatics, with symptoms and signs of asthma but normal spirometry; and 3) 50 healthy controls without any signs and symptoms of asthma and with normal spirometry. After obtaining informed consent, baseline
IOS and spirometry measurement, salbotamul (two puffs, $200 \mu \mathrm{g}$ ) was administered by a metered-dose inhaler via a spacer device. All tests were performed again 15 min later.

As predicted, at baseline, forced expiratory volume in one second (FEV1) was significantly lower in the asthmatic group compared with the probable asthmatics and healthy subjects. Forced vital capacity (FVC) was significantly lower and impedance at $5 \mathrm{~Hz}(\mathrm{Z} 5)$, resistance at $5 \mathrm{~Hz}$ (R5) and resonant frequency (Fres) were significantly higher in asthmatics compared with healthy subjects. Resistance at $20 \mathrm{~Hz}$ (R20) did not differ between the three groups.

In the asthmatic group, FEV1 and FVC significantly increased after bronchodilator use and Z5, R5 and R20 significantly decreased after bronchodilator use. In asthmatics and probable asthmatics, there was a 15-20\% decrease in Z5, R5 and R20 after bronchodilator administration (table 1). However, in some of the healthy subjects a small bronchoconstriction after bronchodilator administration was observed but it was not significant $(\mathrm{p}>0.05)$.

To our knowledge, this is the first study to report the comparison of IOS values to spirometric values in pregnant 


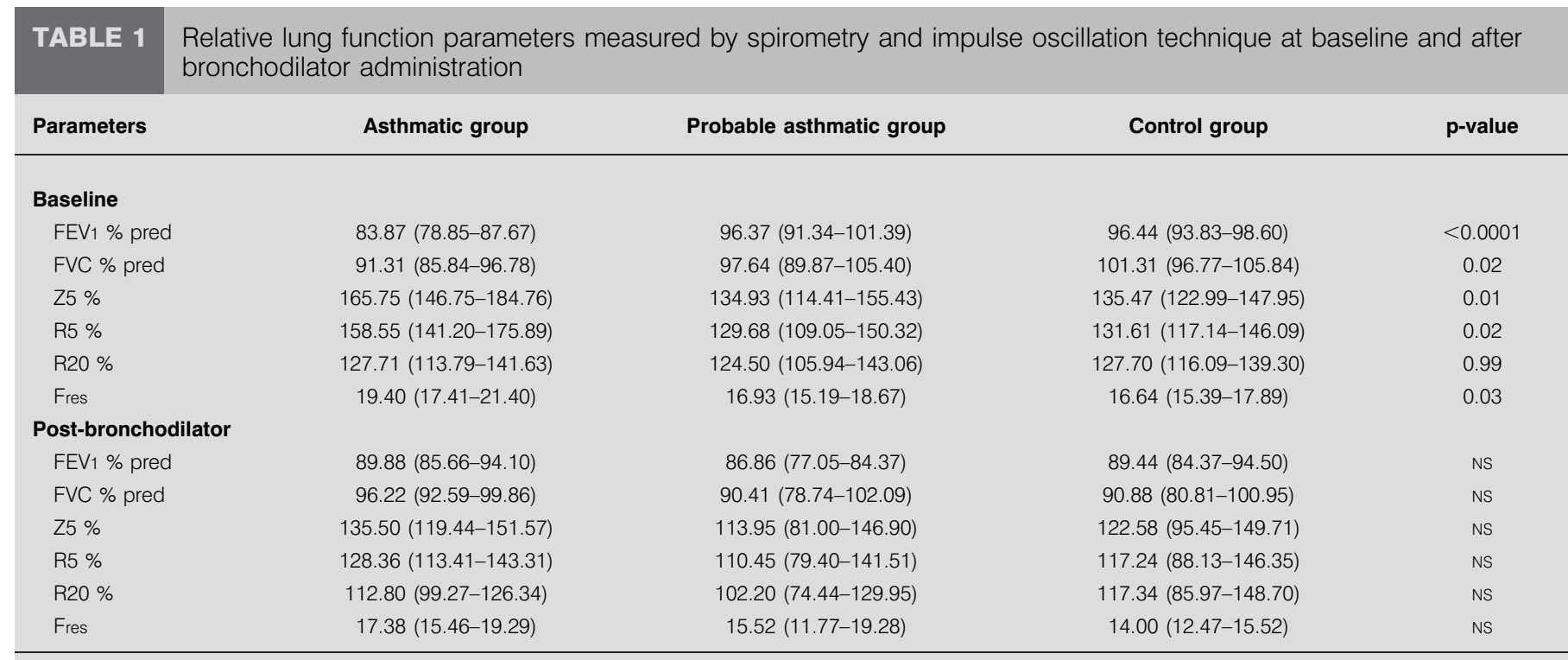

Data are presented as lung function parameters \% predicted (\% pred) mean (95\% confidence). FEV1: forced expiratory volume in one second; FVC: forced vital capacity; Z5: impedance at $5 \mathrm{~Hz}$; R5: resistance at $5 \mathrm{~Hz}$; Fres: resonant frequency; Ns: not significant

asthmatic females. Previous studies have proposed that a decrease of $20-40 \%$ or $>40 \%$ in R5 following bronchodilator use can be considered for a reliable diagnosis of asthma [5-7]. We suggest that a $15-20 \%$ decrease in impedance and resistance at $5 \mathrm{~Hz}$ to be taken as a bronchodilator response in pregnancy. A lower decrease after bronchodilator administration in pregnancy could be due to a reduced total pulmonary resistance and increased airway conductance in pregnancy. We also suggest that baseline and post-bronchodilator responses of Z5 and R5 could be the best IOS parameters for asthma detection in pregnancy.

Our study showed that impulse oscillation technique as a noninvasive and quick method could be used as an appropriate alternative in the screening of pregnant females for asthma. The unique value of this technique in terms of shortterm response to therapeutic challenge [8], especially in symptomatic patients with normal spirometry, should be considered as well. It should be remembered that the measurement of respiratory impedance does not enable the distinction between obstructive and restrictive lung disorders [9]. Further investigations are needed to establish well defined reference values and reversibility criteria. It is better to account for foetal sex as well, because some studies suggest that foetal sex could affect asthma and airway lability [10]. Thus, it may also have an affect on lung function tests and bronchodilator responses.

\section{K. Bidad*,\#, H. Heidarnazhad ${ }^{\uparrow}$, A. Kazemnejad ${ }^{+}$ and Z. Pourpak*}

*Immunology, Asthma and Allergy Research Institute, "Dept of Immunology, Faculty of Medicine, Tehran University of Medical Sciences, "National Research Institute of Tuberculosis and Lung Disease, Shaheed Beheshti University of Medical
Sciences, and ${ }^{+}$Dept of Biostatistics, School of Medical Sciences, Tarbiat Modares University, Tehran, Iran.

\section{STATEMENT OF INTEREST}

None declared.

\section{REFERENCES}

1 National Asthma Education and Prevention Program. Working Group Report on Managing Asthma During Pregnancy: Recommendations for Pharmacologic Treatment. Update 2004. Bethesda, U.S. Department of Health and Human Services, National Institutes of Health, National Heart, Lung, and Blood Institute, 2005.

2 Dommbrowski MP. Asthma and pregnancy. Obstetrics and Gynecology 2006; 108: 667-681.

3 Stone S, Nelson-Piercy C. Respiratory disease in pregnancy. Obstet Gynecol Reprod Med 2007; 17: 140-146.

4 NAEPP Expert Panel Report Guidelines for the Diagnosis and Management of Asthma: Update on Selected Topics 2003. NIH Publication No. 02-5075. National Institutes of Health, National Health, Lung, and Blood Institute. Washington, U.S. Government Printing Office, 2002.

5 Marotta A, Klinnert MD, Price MR, Larson GL, Liu AH. Impulse oscillometry provides an effective measure of lung dysfunction in 4-year-old children at risk for persistent asthma. J Allergy Clin Immunol 2003; 112: 317-322.

6 Song TW, Kim KW, Kim ES, Park JW, Sohn MH, Kim KE. Utility of impulse oscillometry in young children with asthma. Pediatr Allergy Immunol 2008; [Epub ahead of print PMID: 18331417].

7 Nielson KG. Forced oscillation technique. Paediatr Respir Reviews 2006; 7: Suppl. 1, S8-S10.

8 Smith HJ, Reinhold P, Goldman MD. Forced oscillation technique and impulse oscillometry. In: Gosselink R, Stam H, eds. 
Lung Function Testing. Eur Respir Mon 2005; 31: pp. 72-105.

9 Oostveen E, Macleod D, Lorino $\mathrm{H}$, et al. The forced oscillation technique in clinical practice: methodology, recommendations and future developments. Eur Respir J 2003; 22: 1026-1041.
10 Kwon HL, Belanger K, Holford TR, Bracken MB. Effect of fetal sex on airway lability in pregnant women with asthma. Am J Epidemiol 2005; 163: 217-221.

DOI: $10.1183 / 09031936.00091508$ 